Purdue University

Purdue e-Pubs

\title{
Development of a Set of Pre-class Videos for Electromagnetic Theory
}

Benjamin McPheron

Anderson University - Indiana, bdmcpheron@anderson.edu

Josiah D. Kunz

Anderson University - Indiana, jdkunz@anderson.edu

Follow this and additional works at: https://docs.lib.purdue.edu/aseeil-insectionconference

Part of the Electromagnetics and Photonics Commons, and the Engineering Education Commons

McPheron, Benjamin and Kunz, Josiah D., "Development of a Set of Pre-class Videos for Electromagnetic Theory" (2019). ASEE ILIN Section Conference. 5.

https://docs.lib.purdue.edu/aseeil-insectionconference/2019/technology/5

This document has been made available through Purdue e-Pubs, a service of the Purdue University Libraries. Please contact epubs@purdue.edu for additional information. 


\title{
Development of a Set of Pre-class Videos for Electromagnetic Theory
}

\author{
Benjamin D. McPheron, Josiah D. Kunz
}

One important aspect of experiential learning is allowing students time to reflect on new concepts before the application of the material. Most commonly, this is attempted by assigning readings from a textbook, but research suggests that few students complete these readings. This discouraging fact has prompted the use of other resources, such as videos, to supplement pre-class readings in order to introduce new material. Previous work has been completed by this author to produce pre-class videos for use in an introductory circuits course. This paper extends that work to the development of pre-class videos for a senior level electrical engineering course in electromagnetic theory at Anderson University. Although the videos were developed for this course, many of the topics are also applicable to calculus-based physics courses on electromagnetics. As a result, a sophomore level Physics 2 course made use of some of the videos. To improve upon the existing resources, a set of 15 videos were created for use in an electromagnetic theory class. The videos are freely available on YouTube, without advertisements. This paper describes the conception and creation of these videos. Furthermore, this work contributes to the field of engineering education by providing a freely available set of videos that other instructors may use to increase student engagement and learning. Assessment of the initial use of these videos with a small sample group indicate that the target audience watched the videos, felt that the videos helped them do better in the course, felt better prepared for class because of the videos, and valued the videos as a resource. The results indicate that $100 \%$ would recommend the videos to students taking Electromagnetic Theory at another university, and 100\% wish they had pre-class videos for their other courses. When asked how much they would pay for the resource, the average response was $\$ 45$.

\section{Introduction}

An easy way to enhance student ownership of their learning is to provide students with an active role in lecture. To allow active participation in a traditional lecture format, students should be prepared in advance to contribute to the discussion of new material. If students are unprepared for class, it is difficult to have a meaningful discussion on new material, as students have not had time to reflect on new material $[1,2]$.

The most common strategy to facilitate student preparation is to assign readings from textbooks. Unfortunately, research suggests that students take advantage of few textbook features, preferring to use the text as a reference, rather than a self-study guide [3]. Another study suggests that as few as $24.8 \%$ of students read the textbook prior to class [4]. The results of these studies are discouraging for the faculty member who wishes to actively engage their students into lecture. One alternative to pre-class readings to help students prepare for class is to instead use video as the medium to introduce new material prior to class.

One particularly difficult topic for students to conceptualize is electromagnetic theory. In many universities, this course is taught with a primarily theoretical bent, and the content is fairly abstract. In addition to theoretical knowledge, this course also makes heavy use of multivariable calculus, which can further impede understanding even for students with adequate mathematical preparation $[4,5]$. Based on prior experiences with this subject matter, it is clear that this is true for both senior level electrical engineers and students in a sophomore level calculus-based physics course. 
While there are a variety of existing videos covering electromagnetics topics on YouTube, most available videos are overly theoretical and assume significant prior knowledge on the material, making them inaccessible to many students. In addition, many of these videos are long (longer than 5 minutes), and monetized by running advertisements, which may deter students from watching [1].

To improve upon the existing resources, a set of 15 videos were created for use in electromagnetic theory courses. The videos are split into two types: those that describe the vector calculus tools necessary for electromagnetics problems, and those that introduce new theoretical topics. The former are short videos that cover the important steps of necessary mathematical skills. The latter videos relate electromagnetics topics to real world ideas through analogy or anecdote and include humor in an attempt to make the videos accessible to a student audience. The videos are freely available on YouTube, without advertisements and are presented in this paper as a resource to other engineering educators interested in adopting them in their electromagnetic theory courses.

These videos were implemented by a faculty member new to Anderson University, in a course with a small student population. As a result, direct assessment of the impact of these videos was not feasible. Instead, indirect assessment was performed to examine the efficacy of these videos. The specific assessment questions that were addressed through student survey included:

AQ1: Did students watch the videos?

AQ2: Did students feel they performed better because of the videos?

AQ3: Did students feel that they were better prepared for class because of the videos?

AQ4: Did students value the videos?

\section{Literature Review}

The following literature review is partly based on the recently completed study by this author [1] but has been adapted significantly to address key differences in the current work. The literature contains numerous examples and descriptions of methods employed in an attempt to increase the quality and amount of pre-class preparation. Methods to improve pre-class preparation can be classified into those that employ reading a traditional, printed text, and those that do not. In the literature, some of the studies are evidence based, employing some form of direct assessment, while others are written more as resources for instructors to try new methods, which is the case of the current work.

Several methods that have been tested or suggested to improve reading rate and effectiveness of traditional textbook readings. Some methods use graded artifacts as motivations to encourage reading the textbook, including requiring students to complete a reading exercise connected to the reading $[6,7,8]$, using in-class quizzes $[9,10,11]$, and/or testing on material in the text that was not covered in lecture [9, 11]. Other options include assigning shorter readings [9], preparing precollege students to use textbooks successfully $[12,13]$, awarding extra credit $[10,14]$, adopting textbooks early [15], and using in-class activities to demonstrate the intrinsic importance of reading [16].

Among the many non-textbook based methods, potentially most prevalent is the use of video in the context of "flipped" lectures, in which students are delivered lecture material prior to class, and the traditional class time is used for application of this material to problems, projects, or experiential learning $[5,17,18]$. Other methods include use of e-text books $[19,20,21]$ and the use of web-facilitated discussion tools $[22,23]$. Most relevant to this study are works documenting 
use of video or multimedia presentations a similar manner as in this study [1, 5, 24, 25, 26, 27] which we describe more fully below.

Most analogous to the work in this paper was a study completed by McPheron, et al. [1], in which a set of 20 pre-class videos were produced for a circuit theory course. These videos included similar elements to the present study, such as humor and application of anecdote. The use of these videos was assessed using both direct and indirect means. The results indicated that $85 \%$ of the students felt that the videos helped them prepare for class, and $92 \%$ would recommend the videos to students taking Circuit Theory at another university. When asked how much they would pay for the set of videos, the average response was $\$ 19.30$. The videos may have also had a positive impact on student learning. Students having access to the videos scored $8.36 \%$ higher on the final exam than did comparable students taking the same exam the previous year.

Specific examples of use of videos in electromagnetic theory courses include studies by Young, et al. [5] and Steltzer, et al. [24]. In the study by Young, et al., students were asked to watch preclass videos and complete a quiz prior to lecture in an electrostatics course. Stelzer, et al. describe the use of multimedia learning modules (MLM) to support an introductory electricity and magnetism course at the University of Illinois at Urbana-Champaign. They implemented this system in 2008 after they discovered, to their surprise, that a majority of their students reported that they were not preparing for class by reading the assigned reading, despite requiring the students be able to answer questions based on the reading. In this case, the authors prepared a series of 4 multimedia modules containing animations and audio narration. The length of each module was around 12 minutes. To investigate the effectiveness of the approach, the authors split the volunteer population up into three groups: one that used the multimedia modules, another that read the script for the modules, and a third that did assigned readings. Their results suggest that the multimedia modules can have a significant positive impact on post-lesson assessment, and student exam performance, improving on the exam by almost a full standard deviation (13.5\%) with an effect size of 0.85 (large effect). Sadaghiana [25] reports using the same MLMs at California State Polytechnic University, Pomona. Their study indicates that students would rather view the MLMs than read the text and consider the MLMs beneficial to their learning.

Fraley, et al. [26] implemented the use of pre-lesson videos and quizzes for a first-year engineering course in the fall of 2014 at Michigan Technological University. Their motivation was, as in the other studies, to increase the quality and amount of student preparation for class. In their case, they divided a sample population into three subsets. Group 1 followed the established, traditional course format, Group 2 was allowed to watch the videos, and Group 3 could watch, and also had to complete a short online quiz that drew from the video. All three group were permitted to do the traditional course reading. They prepared roughly 30 videos on a number of topics, but mostly on software instruction (Excel and MATLAB). Based on analysis of scored course assessments, they concluded that watching the videos leads to an increase in score, suggesting that the students who watch the videos learn the course material more effectively.

In addition to work done to study the effectiveness of video content used for pre-class preparation, one group at the University of Notre Dame [27] describes an alternate use that is worth noting: as a means for preparing students for their second year in the engineering curriculum. Goodrich, et al. report that they created a series of videos for students to watch during the summer break before their second year, on topics for all engineering disciplines and for specific ones. The system was implemented in the summer of 2016. Although watching the videos is optional for the students, 
they report that about 80 percent of the possible users visited the hosting site at least once. Whether this activity has a positive influence on their learning is not a topic of their study but given that such a large percentage of students took advantage of the opportunity, it seems worthy of further development.

Focusing on features specific to the videos described in this work, important aspects include short length and humor. Videos created for this study were an average of 3:11 in length, with the longest being 5:30 (Smith Charts) and the shortest being 1:55 (Computing a Volume Integral). These video lengths are consistent with a rule of thumb that has emerged when creating online educational videos - online videos should be less than 6 minutes in length [28]. However, we note that there is not universal agreement on this rule [29, 30,31]. Many of the videos produced include an element of humor as a means of engaging students. Humor has been studied as a means for creating a classroom environment that is conducive to student learning in STEM fields [32, 33]. There is also evidence that suggests that videos produced with a "more personal feel" (which could include humor) can be more engaging [28].

\section{Video Production}

The videos produced for this study cover the topics shown in Table 1. These topics are commonly covered in engineering electromagnetics courses, and several are covered in lower level calculusbased physics courses [34].

Table 1: Video Topics

\begin{tabular}{|c|c|c|}
\hline Vector Calculus Tools & \multicolumn{2}{|c|}{ Electromagnetic Theory } \\
\hline Divergence & Coulomb's Law & Faraday's Law \\
\hline Curl & Gauss's Law & Phasors \\
\hline Dot \& Cross Products & Electric Scalar Potential & Smith Charts \\
\hline Basic Line Integration & Biot-Savart Law & Impedance Matching \\
\cline { 1 - 2 } Basic Surface Integration & Ampere's Law & \\
\cline { 1 - 2 } Basic Volume Integration & \multicolumn{2}{|}{} \\
\cline { 1 - 2 } & &
\end{tabular}

The videos on vector calculus tools are structured so that they cover all important steps for each procedure, and then provide an example of the application of the tool. In this video, the presenter is unseen, relying on efficiently communicating the information in a short format to make these videos attractive. As an example, a screenshot from the video on the dot and cross product is shown in Figure 1. 


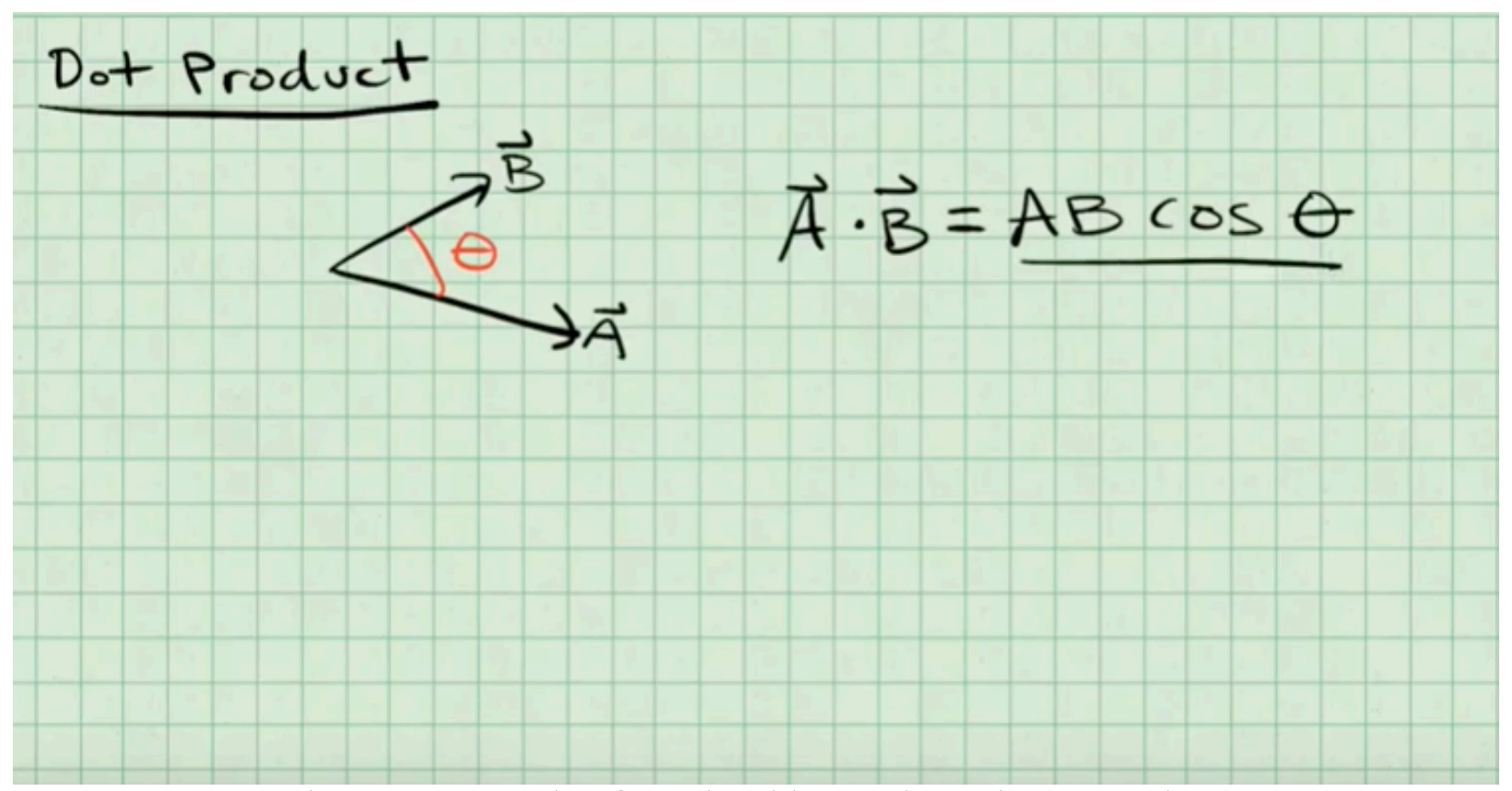

Figure 1: Screenshot from the video on dot and cross product.

The videos covering electromagnetic theory makes use of anecdotes and references from real life or pop culture to relate non-technical real-world experiences to technical, theoretical topics. Some of these videos include a worked-out example (particularly the Smith Chart video and Impedance Matching video), but not all. In these videos, the presenter speaks to the camera, allowing the audience to connect with the presenter. In addition, a variety of images which make use of pop culture references or puns are shown which relate to what is being said in a humorous way [35].

The videos on vector calculus tools were produced by using the screen capture feature of an iPad to record handwritten theory and examples. Once this screen capture was performed, the file was edited to remove dead space and goof ups. Then, a script was written, audio recorded and edited, and additional editing performed on the video. The exported file was then uploaded to YouTube and shared with the students through the course management system.

For the videos on Electromagnetic Theory topics, a significantly more detailed procedure was employed. That procedure is detailed here for those wishing to implement something similar for other courses. The following steps were employed:

1. Write and revise a script for the video

2. If there is a need for handwritten work in the video, use the screen capture feature of an iPad to record handwritten theory and examples using the application Notability.

3. Revise the script if deemed necessary by changes to the handwritten section.

4. Record the live video. A number of cameras were used, but an iPhone's rear facing camera set to capture $1080 \mathrm{p}$ or $4 \mathrm{k}$ resolution was often the best option.

5. During live recording, audio is captured through a Blue Yeti USB microphone connected to an Apple MacBook Pro, using Garage Band set to Narration Vocal Input.

6. Transfer video and audio files into iMovie.

7. First editing pass to synchronize audio and video and remove mistakes made in recording, cutting the length down as much as possible while retaining the essential elements.

8. Add intro and outro bumpers. 
9. Add humorous annotations and topical references relevant to discussion. Most images used are found in Wikimedia Commons, chosen because images are free license or public domain.

10. Final check of video to review any mistakes.

11. Export to file, $\mathrm{m} 4 \mathrm{v}$ is standard iMovie encoding.

12. Upload file to YouTube and back up all raw and edited files.

The entire production process required 4 or more hours for each video. While this initial cost is very high, it is intended that these videos will be used for many years to come, and that other universities may adopt them as a resource. The playlist containing all of the videos can be found at https://www.youtube.com/DMExplains, in the Dr. McPheron Explains Electromagnetics playlist (https://bit.ly/2EtLtcK). To give the reader a feel for the particular style of these videos, a screenshot is shown. Figure 2, captured from the video on Ampere's Law, displays an image of Stretch Armstrong as the presenter points out that the particular transition is "a bit of a stretch".

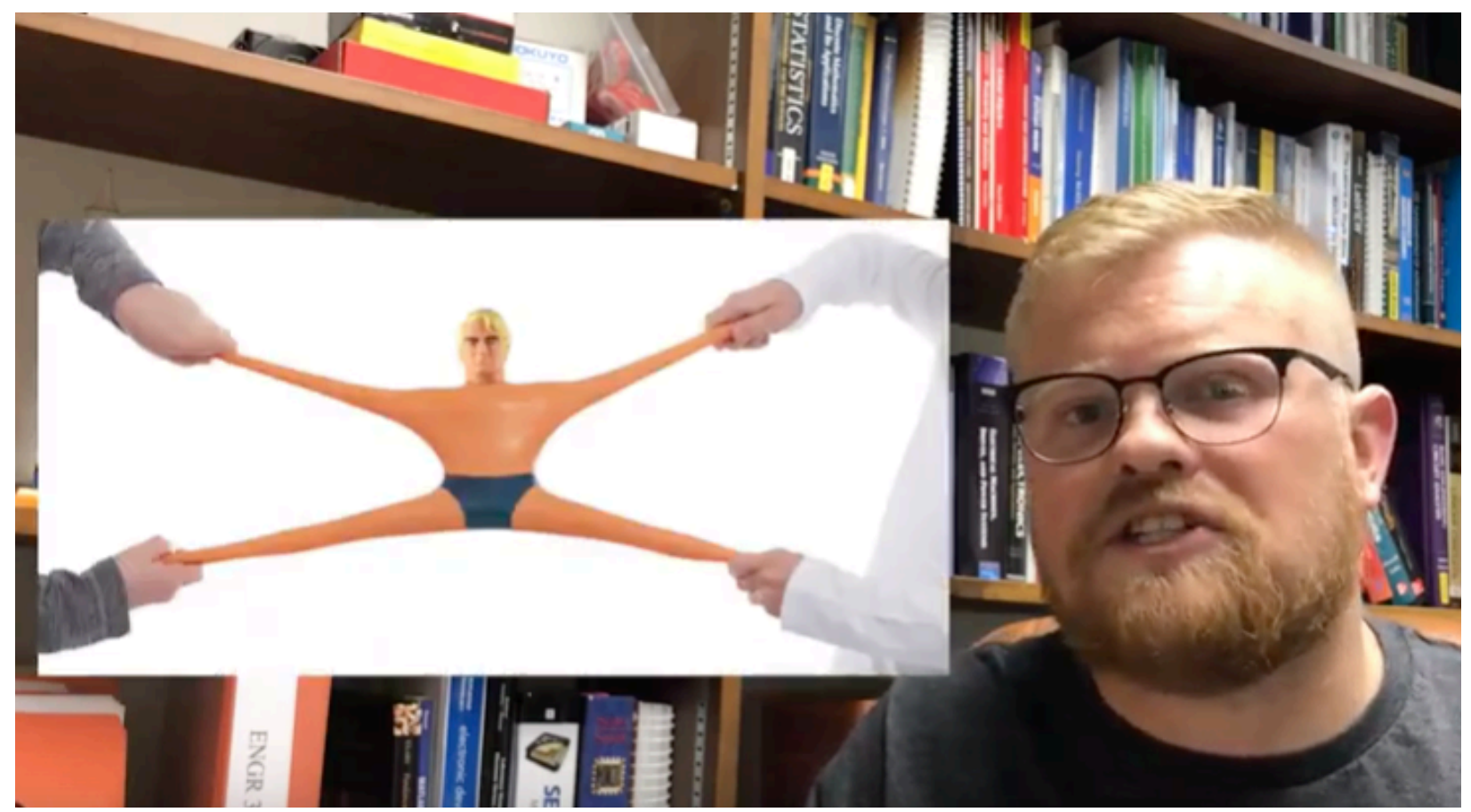

Figure 2: "A bit of a stretch".

\section{Assessment and Future Assessment Plan}

The videos described in this work were used, to varying degrees in both a senior level electromagnetics 1 course for electrical engineering majors (this course is referred to as ENGR EMAG hereafter), and a sophomore level physics course which covers electromagnetics for both engineering majors and non-engineering majors (referred to as PHYS 2 hereafter). In the ENGR EMAG course, the videos were emphasized as a learning tool and posted on the course management system website. In the PHYS 2 course, the videos were mentioned once or twice early in the course (much before the actual electromagnetics section) and also posted on the course management system website. As a result, few of the students in the PHYS 2 course made use of the videos, and those who did watched only a few. 
To assess the efficacy of these videos and to attempt to answer the research questions, the students who made use of the videos were surveyed. The total number of respondents were $1 / 1$ from the ENGR EMAG course, and 2/11 from the PHYS 2 course. Because the sample size and response rate are both very low, no concrete conclusions can be drawn from this survey. However, the results provide basic guidance and can spark some ideas of how to improve the deployment of these videos in future offerings.

The student survey included seven 5-point, Likert scale items, with 1 being 'Strongly Disagree' and 5 being 'Strongly Agree'. Students were asked to rate agreement with the following statements, appended with the assessment question they address.

1. These videos were helpful in teaching or refreshing math skills needed for electromagnetics. (AQ3)

2. If I had watched all of the videos I would have performed better in the course. (AQ2)

3. If I had watched all of the videos, I would have understood material better in the course. (AQ2)

4. These videos were helpful in introducing theoretical information for electromagnetics. (AQ3)

5. If I didn't have pre-class videos, I still would have prepared for class by reading the textbook. (AQ3)

6. I wish I had pre-class videos in my other courses. (AQ4)

7. I would recommend these videos to other students taking electromagnetic theory at other universities. (AQ4)

In addition to the Likert scale survey questions, students were asked to rate how many videos they watched (AQ1) and were asked to place a dollar value on the resource (AQ4).

The results of the seven Likert-scale items are shown in a 100\% stacked bar chart (Figure 3), which allows for clear observation of agree responses and disagree responses [36]. 
1. These videos were helpful in teaching or refreshing math skills needed for electromagnetics

2. If I had watched all of the videos I would have performed better in the course

3. If I had watched all of the videos, I would have understood material better in the course

4. These videos were helpful in introducing theoretical information for electromagnetics

5. If I didn't have pre-class videos, I still would have prepared for class by reading the textbook

6. I wish I had pre class videos in my other courses

7. I would recommend these videos to other students taking electromagnetic theory at other universities

—Strongly Disagree $\quad$ Disagree



Neutral $\square$ Agree $\square$ Strongly Agree

Figure 3: Results of survey data.

With regards to the assessment questions posed in the Introduction section, the results of the student survey suggest that:

1. The ENGR EMAG student watched the videos, indicating that they watched between $65 \%$ and $85 \%$ of the videos. This result being less than $100 \%$ may be due to the review nature 
of the videos on multivariable calculus. The student in this course was well prepared mathematically for these topics. The PHYS 2 students indicated far lower viewership with one indicating watching 0-2 (0-14\%) and the other indicating 3-5 videos watched $(21 \%$ $35 \%$ ). This could be due to the lack of emphasis on these videos in the PHYS 2 course.

2. Students generally feel that they performed better because of the videos or would have performed better if they had taken advantage of the resource. The average rating for the prompt "If I had watched all of the videos I would have performed better in the course" was 4.00, with no respondents disagreeing with the prompt. With such a small sample size, the standard deviation is not worth reporting. The average rating for the prompt "If you had watched all of the videos, I would have understood material better in the course" was 3.33 , with 2 of 3 respondents indicating agreement.

3. Students felt that they were better prepared for class thanks to the videos. The average rating for the prompt "These videos were helpful in teaching or refreshing math skills needed for electromagnetics" was 4.00, with 2 of 3 respondents indicating agreement. The average rating for the prompt "These videos were helpful in introducing theoretical information for electromagnetics" was 4.33 , with no respondents disagreeing. The prompt "If I didn't have pre-class videos, I still would have prepared for class by reading the textbook" was reverse coded to combat acquiescence bias. As a result, a lower rating is more desirable. The average result for this prompt was 2.67, with 2 of 3 respondents indicating disagreement.

4. Students valued the videos. In response to the prompt, "I wish I had pre-class videos in my other courses", $100 \%$ of the students indicated agreement, for an average rating of 5. The average rating for the prompt "I would recommend these videos to other students taking electromagnetic theory at other universities" was 4.67 , with $100 \%$ of students indicating agreement. Finally, the students indicated they would pay an average of $\$ 45$ for these videos if they were offered as a resource for the course.

With the low number of participants and respondents, these results do not provide sufficient data to draw meaningful conclusions. However, the limited results are promising. It is notable that negative responses to each prompt were the same respondent who indicated 0-2 videos watched.

In the future, additional assessments for retention of information, such as video quizzes, could prove fruitful. To assess popularity, the YouTube views could be tracked over time and corroborated topically or with exam dates. Moreover, contrasting results between a control and experimental group, provided that class sizes are sufficiently large, would strengthen the results. For further granularity in the data, it would have been valuable to consider the cohort in PHYS 2 separately from the cohort in ENGR EMAG, but this was infeasible in this study due to sample size.

\section{Conclusions and Discussion}

This paper describes the production of a set of 14 short pre-class videos to help prepare students for lessons in electromagnetic theory courses. Many of these videos employ humor and topical references, as well as adhere to the well-known recommendation to keep instructional videos short. The videos are available for free on YouTube, do not employ advertisements, and are presented in this paper as a resource to other engineering and physics educators interested in adopting them in their electromagnetic theory courses. 
While the sample size for the initial deployment was small, the initial assessment results were generally positive. Further work is required to assess the impact of the use of these videos on student performance. In the future, these videos will be reused and the impact on students learning will be assessed more directly.

Some important lessons learned bear emphasis. One lesson is that for these videos to be successfully deployed, appropriate emphasis by the instructor on the value and importance of this resource is necessary. In addition, it takes significant time to develop these resources. In order to offset the high initial cost in time and effort, it is important that the resources get used by as many students as possible over a number of course offerings.

\section{Acknowledgements}

The authors would like to thank Charles R. Thomas, Ph.D., for his many contributions to the literature review process.

\section{References}

[1] B.D. McPheron, C.R. Thomas, W.J. Palm "Time for Reflection: Development of Twenty Short Videos to Introduce New Topics and Engage Students in Circuit Theory." 2018 ASEE Annual Conference and Exposition, June 24-27, 2018.

[2] B.D. McPheron, C.V. Thangaraj, C.R. Thomas. "A Mixed Learning Approach to Integrating Digital Signal Processing Laboratory Exercises into a Non-Lab Junior Year DSP Course." Advances in Engineering Education, Spring 2017, Vol. 6, Issue 1.

[3] C.S. Lee, N.J. McNeill, E.P. Douglas, M.E. Koro-Ljungberg, D.J. Therriault. "Indispensable Resource? A Phenomenological Study of Textbook Use in Engineering Problem Solving.” Journal of Engineering Education, Vol. 102, No. 2, pp. 269-288, April 2013.

[4] B.M. Notaros, R. McCullough, S.B. Manic, and A.A. Maciejewski. "Board\# 51: WIP: Introducing MATLAB-based Instruction and Learning in the Creativity Thread of a Novel Integrated Approach to ECE Education." 2017 ASEE Annual Conference \& Exposition. 2017.

[5] M.G. Young, J.P. Conry, E.C. Greco Jr. "WIP: Implementation of Electrostatics Tutorials Utilizing an Electronic Response System" 2018 ASEE Annual Conference and Exposition, June 24-27, 2018.

[6] K. Cummings, T. French, P.J. Cooney. "Student Textbook Use in Introductory Physics." PERC Proceedings (2002) (Accessed from: https:/www.compadre.org/per/items/detail.cfm?ID=4374 on January 19, 2018.

[7] Connor-Greene, P. A. (2005). Fostering meaningful class-room discussion: Studentgenerated questions, quotations, and talking points. Teaching of Psychology, 32, 173-175.

[8] A. Uskul, J. Eaton, (2005). Using graded questions to increase timely reading of assigned material. Teaching of Psychology, 32, 116-118.

[9] L. Aagaard, T. Conner, R. Skidmore. "College textbook reading assignment and class time activity." Journal of the Scholarship of Teaching and Learning. 14:3, August 2014, 132-145.

[10] Lei, S. A., Bartlett, K. A., Gorney, S. E., \& Herschbach, T. R. (2010). Resistance to reading compliance among college students: Instructor's perspectives. College Student

Journal, 44(2), 219-230.

[11] M. French, F. Taverna, M. Neumann, L. Kushnir, J. Harlow, D. Harrison, R. Seranescu. "Textbook use in the Science and its Relation to Course Performance." College Teaching. 63: 171 $-177,2015$.

[12] G. Ragusa. "Science Literacy and Text Book Biases" Proceedings of the $120^{\text {th }}$ ASEE Annual Conference and Exposition, Paper ID 7508, Atlanta Georgia, June 23-26, 2013. 
[13] D. Reeping, K. Reid. "Work in Progress: Methods Implemented by a Non-Traditional Textbook to Enable Student Success in Engineering." Proceedings of the $121^{\text {st }}$ Annual ASEE Conference and Exposition, Paper 8415, Indianapolis Indiana, June 15-18, 2014.

[14] Clump, M. A., Bauer, H., \& Bradley, C. (2004). The extent to which psychology students read textbooks: A multiple class analysis of reading across the psychology curriculum. Journal of Instructional Psychology, 31(3), 227-232.

[15] J. Cannon, P. Brickman. "Assigning Textbook Early Can Save Money and Enhance Learning." Journal of College Science Learning, 44:5, 38-41, 2015.

[16] M. Kerr, K. Frese. "Reading to Learn or Learning to Read? Engaging College Students in Course Readings." College Teaching. 65:1, 28-31, 2017.

[17] E.F. Gehringer. "Resources for 'flipping' classes." Proceedings of the $122^{\text {nd }}$ ASEE Annual Conference and Exposition, Paper ID 12823, Seattle, June 14 - 17, 2015.

[18] O. Egbue. "Incorporating Active Learning Strategies into An Engineering Economics Course." 2018 ASEE Annual Conference and Exposition, June 24-27, 2018.

[19] P. Richards. "Proximity of Equations, Text, and Figures in Civil Engineering ETextbooks." Proceedings of the 120 ASEE Annual Conference and Exposition, Paper ID 6060, Atlanta Georgia, June 23-26, 2013.

[20] K. Jackson, R. Vander Wal. "Taking matters into your own hands: is creating an e-textbook for you?" Proceedings of the $119^{\text {th }}$ ASEE Annual Conference and Exposition, San Antonio June 10-13, 2012.

[21] A. Edgcomb, F. Vahid, R. Lysecky, A. Knoesen, R. Amirtharajah, M. Dorf. "Student Performance Improvement using Interactive Textbooks: A Three-University Cross-Semester Analysis." Proceedings of the $122^{\text {nd }}$ ASEE Annual Conference and Exposition.

[22] M. Liberatore. "Annotations and Discussion of Textbook and Papers using a Web-based System (Work in Progress)." Proceedings of the $124^{\text {th }}$ ASEE Annual Conference and Exposition, Columbus Ohio, June 25 - 28, 2017.

[23] T. Lineweaver. "Online Discussion Assignment Improve Students' Class Preparation." Teaching of Psychology. 37: 204 - 209, 2010.

[24] Stelzer, Timothy, et al. "Comparing the efficacy of multimedia modules with traditional textbooks for learning introductory physics content." American Journal of Physics, 77.2, (2009): 184-190.

[25] Sadaghiani, Homeyra R., "Online prelectures: an alternative to textbook reading assignments," Physics Teacher 50:301-303, 2012.

[26] M. Fraley, A. Hamlin, A. Kemppainen, G. Hein. 'Using Pre-lesson Materials and Quizzes to Improve Student Performance." Proceedings of the $122^{\text {nd }}$ ASEE Annual Conference and Exposition. Seattle, Washington, June 14-17, 2015.

[27] V. Goodrich, L. McWilliams, Y-F. Huang. "Work in Progress: Development of Optional Summer Video Content for Preparation for Sophomore Year, with Initial Finding." Proceedings of the $124^{\text {th }}$ ASEE Annual Conference and Exposition. Columbus Ohio, June 25 - 28, 2017.

[28] P. Guo, J. Kim, R. Rubin. "Video Production Affects Student Engagement: An Empirical Student of MOOC Videos.” Proceedings of L@S 2014, Atlanta Georgia, March 4-6, 2014

[29] L. Lagerstrom, P. Johanes, U. Ponsukcharoen "The Myth of the Six Minute Rule: Student Engagement with Online Videos." Proceedings of the 122 ASEE Annual Conference and Exposition. Seattle, Washington, June 14-17, 2015.

[30] R. Berg, A. Brand, J. Grant, J. Kirk, T. Zimmerman. "Leveraging Recorded Mini-Lectures to Increase Student Learning. 14:2, 5-8, 2014. 
[31] N. Geri, A. Winer, B. Zaks. "Challenging the six-minute myth of online video lectures: Can interactivity explain the attention span of learners?" Online Journal of Applies Knowledge Management. 5:1, 101-111, 2017.

[32] D. Hu, L. Lefton, P. Ludovice "Humour Applied to STEM Education" Systems Research and Behavioral Science. 34:2, 216-226, 2017.

[33] R. Ocon. "Using Humor to Create a Positive Learning Environment." Proceedings of the $122^{\text {nd }}$ ASEE Annual Conference and Exposition. Seattle, Washington, June 14 - 17, 2015.

[34] F.T. Ulaby, U. Ravaioli. "Fundamentals of Applied Electromagnetics." $7^{\text {th }}$ Edition, 2015 Pearson Education, Inc.

[35] J.T. Kao, R. Levy, and N.D. Goodman "A Computational Model of Linguistic Humor in Puns." Cognitive Science 40 (2016) 1270-1285.

[36] N.B. Robbins and R.M. Heiberger. "Plotting Likert and other rating scales", Joint Statistical Meeting, 1058-1066, 2011. 